\title{
Crenças de aprendizes sobre leitura em língua inglesa
}

\author{
Daniela Gomes de Araújo Nóbrega \\ Universidade Estadual da Paraíba - UEPB \\ Dione Barbosa Dantas \\ Universidade Estadual da Paraíba - UEPB
}

\begin{abstract}
Resumo
Considerando que o ensino de leitura em língua inglesa no Brasil vem se tornando cada vez mais necessário, uma vez que a realidade da escola pública não possibilita o desenvolvimento das quatro habilidades (falar, ouvir, ler e escrever), decidimos pesquisar o que acontece numa sala de aula de uma escola pública com relação ao ensino-aprendizagem de leitura. Esta pesquisa investigou as crenças de um grupo de alunos do $2^{\circ}$ ano do Ensino Médio em relação à leitura em Língua Inglesa para discutir suas concepções, motivações e as dificuldades destes alunos em relação a esta habilidade comunicativa. Para isso, foi usado um questionário para coleta de dados. Como base teórica, utilizamos os PCN - LE (1998, 2000), Leffa (1998), Kleiman (2007) e Barcelos (2004). Acreditamos que a pesquisa seja relevante para professores desta língua estrangeira porque, baseando-nos nos resultados deste trabalho, podemos colaborar na elaboração de aulas mais interativas e acessíveis ao mundo dos alunos.
\end{abstract}

Palavras-chave: crenças de alunos; leitura; aulas de língua inglesa.

\begin{abstract}
Assuming that the teaching of reading in English is becoming increasingly necessary, since the reality of public schools in Brazil doesn't allow the development of the four communicative skills, we decided to research the classroom reality from a public institution in what concerns the reading ability. This study investigated the students' beliefs from the 2nd year of high school, about reading in English, to discuss their reading concepts, motivation and difficulties in the process of reading comprehension. For this, we applied a questionnaire for data collection. The theory was based on the PCNs (1998, 2000), Leffa (1998), Kleiman (2007) and Barcelos (2004). We believe that this research is relevant to teachers in the area of English Language since, based on the results of this work, we can collaborate in the development of more interactive and accessible classes toward the learners' world.
\end{abstract}

Keywords: students' beliefs; reading; EFL classes. 


\section{INTRODUÇÃO}

Mesmo após o inglês ter se tornado uma disciplina obrigatória no currículo da educação básica em 1996 (com a criação da Lei de Diretrizes e Bases para a Educação Nacional, LDB), alguns alunos tendem a ser indiferentes às aulas de Língua Inglesa (LI) e parecem considerá-las desnecessárias. Não somente em BRASIL (2000), mas também com base na nossa experiência de ensino em Língua Inglesa, é possível observar que, para muitos professores, o ensino de LI vem se tornando cada vez mais desmotivador: os professores não têm motivação para ensinar e os alunos tampouco têm para aprender.

Com base na minha experiência enquanto aluna de escola pública, e atualmente como professora estagiária, é comum ouvir que os professores trabalham com textos em sala de aula, com base apenas nos livros didáticos ou de material avulso, dependendo do objetivo da aula. Porém, ao estarmos inseridas na realidade escolar, pudemos notar que, mesmo a leitura sendo uma habilidade comumente trabalhada nas escolas, muitas vezes os textos são usados para a compreensão de conteúdos e regras gramaticais da língua, sendo pouco usados para despertar o interesse em ler por parte do aluno.

Tomando como base nossa experiência enquanto aprendizes dessa língua estrangeira, observamos por muito tempo as aulas gramaticais que não nos ensinavam a usar a língua inglesa no cotidiano. Este fato nos motivou a pesquisar esta realidade com mais afinco e desejamos agora, enquanto professoras em formação do curso de LetrasInglês da Universidade Estadual da Paraíba, investigar qual é a percepção dos alunos em relação à leitura em LI.

Partindo do pressuposto que os alunos tendem a não gostar das aulas de inglês, decidimos buscar respostas para refletir sobre o que motiva e/ou desmotiva os alunos em sala de aula. Portanto, nosso objetivo neste trabalho foi investigar as crenças de um grupo de alunos do $2^{\circ}$ ano do Ensino Médio em relação à leitura em LI no que se refere ao ensino e aprendizagem de leitura em sala de aula. Como objetivos específicos, procuramos (1) apresentar as crenças dos alunos sobre a habilidade de leitura em LI para (2) identificar os fatores (des)motivadores dos alunos na leitura e (3) descrever as principais dificuldades destes alunos na prática de leitura.

Acreditamos que esta pesquisa se torna relevante para professores da área de Língua Inglesa por discutir sobre a percepção que os alunos têm da disciplina, com foco na leitura, pelo fato de ser tal habilidade a mais trabalhada na rede pública de ensino e recomendada pelos PCN-LE (1998). Entendemos que, em diferentes contextos de ensino-aprendizagem, 
identificar e discutir sobre a percepção dos alunos em leitura é importante para ajudar o professor a verificar suas preferências, dificuldades e o grau de motivação com vistas à leitura em LI, e, assim, poder alcançar resultados de aprendizagem mais satisfatórios na sala de aula e na vida destes alunos.

\section{A LEITURA NA ESCOLA}

Há muito tempo que o ensino de Língua Estrangeira (LE) no Brasil vem sendo debatido. Na época do império, a Língua Estrangeira era considerada importante, mas foi perdendo seu prestígio ao longo dos anos. Segundo Paiva (2003), a LDB de 1961 e a de 1971 ignoraram a importância das línguas estrangeiras ao deixar de incluí-las dentre as disciplinas obrigatórias do currículo. Em 1976, o ensino de LE foi declarado obrigatório apenas para o Segundo Grau (Ensino Médio), continuando em caráter optativo para o Primeiro Grau (Ensino Fundamental). Vinte anos depois, o ensino de LE foi fixado e, em 1996, tornou-se obrigatório.

Atualmente, as línguas inglesa e espanhola são as duas ensinadas nas escolas brasileiras. A escolha do espanhol foi determinada pela sua importância em aspectos políticos, econômicos e sociais. Para os PCN-LE do Ensino Fundamental (1998, p. 50), "sua crescente importância, devido ao MERCOSUL, tem determinado sua inclusão nos currículos escolares, principalmente nos estados limítrofes com países onde o espanhol é falado". Porém, mesmo sendo uma língua importante para o contexto brasileiro, o ensino do espanhol ainda está se estabelecendo no Brasil. Assim, a Língua Inglesa (LI) é a principal LE ensinada nas escolas.

Para Gadriot-Renard (2005), a LI tem se estabelecido como língua franca por ser o idioma de mais fácil acesso e comunicação entre países. Isto ocorre porque a LI é também a língua que domina a mídia, a economia, a tecnologia e a ciência. Estes fatores contribuíram para a efetivação do ensino de LI como principal LE no currículo da educação básica do país.

Mesmo tornando-se uma disciplina obrigatória na grade curricular nas escolas, o ensino-aprendizagem da LI ainda enfrenta grandes problemas, relacionados a diversos fatores. Tendo como referência minha experiência como aluna de língua inglesa no curso Letras- Língua Inglesa e agora como professora, estes fatores incluem desde a formação de profissionais, a escassez de recursos e materiais didáticos à lotação de alunos nas salas de aulas nas escolas públicas. 
Esses fatores tendem a comprometer o desenvolvimento do ensino-aprendizagem de LE, uma vez que "em lugar de capacitar o aluno a falar, ler e escrever em um novo idioma, as aulas de Línguas Estrangeiras Modernas nas escolas [...] acabaram por assumir uma feição monótona e repetitiva que, muitas vezes chega a desmotivar professores e alunos [...]" (PCNEM, 2000, p. 25). Ou seja, mesmo sendo considerada uma disciplina indispensável ao currículo dos alunos, as aulas de LI ainda possuem características desmotivadoras por serem pautadas no estudo de formas gramaticais e na tradução de textos, resultando em aulas descontextualizadas e distantes da realidade dos alunos.

Em consonância com os PCN-LE (1998) para o Ensino Fundamental, as condições das salas de aula no Brasil não possibilitam o ensino das quatro habilidades (falar, ouvir, ler e escrever). É dito que a leitura "atende (...) às necessidades da educação formal, e, por outro lado, é a habilidade que o aluno pode usar em seu contexto social imediato" (PCNs, 1998, p.20). Desta forma, sugere-se que a leitura deva ser a habilidade mais trabalhada na Educação Básica, não excluindo a possibilidade de as outras três serem também abordadas.

Deste modo, recomenda-se o desenvolvimento da habilidade de leitura nas escolas, pois o uso de uma LE no Brasil está, em grande parte, relacionado à leitura de textos com objetivos específicos. Ou seja, as pessoas leem um texto em LE para obter aprovação em exames formais, vestibulares e concursos.

\section{DEFININDO LEITURA}

Ler é um processo em que estão envolvidos três elementos: o leitor, o texto, e o autor do texto. De acordo com Leffa (1996, p. 11), existem quatro principais definições de leitura. Uma geral, duas específicas e uma conciliatória. Na definição geral, "ler é, na sua essência, olhar para uma coisa e ver outra" (LEFFA, op.cit, p. 11). Neste caso a leitura é vista como processo de representação, ou seja, vemos uma coisa, e a partir desta visão deduzimos outra coisa que pode, ou não, estar relacionada à primeira. Um exemplo que ilustra esta definição é, ao ver uma pessoa bem vestida, com um bom carro, deduzimos que esta pessoa é rica. Esta é uma leitura que fazemos e que pode ou não estar de acordo com o fato.

Ainda de acordo com Leffa (1996), temos duas definições que se opõem. A primeira afirma que "ler é extrair significado do texto" (op. cit., p.11), e a segunda afirma que "ler é atribuir significado ao texto". Na primeira definição, a leitura é tida como ato de exploração, ou seja, o leitor lê e explora todo o texto, com o máximo de atenção, 
observando os detalhes, e assim chega a uma compreensão precisa do texto. Deste modo, o leitor não se mistura ao texto, apenas absorve o seu conteúdo. Na segunda definição, a leitura envolve o leitor, e a compreensão do texto vai depender das atribuições de significado feitas por este leitor. Assim, um mesmo texto pode ter valores semânticos diferentes, dependendo de quem o lê.

$\mathrm{Na}$ definição conciliatória de leitura, Leffa (1996) propõe uma interação entre texto e leitor, que podemos entender da seguinte forma:

\begin{abstract}
Para melhor explicar esse processo de interação entre leitor e texto, vamos fazer uma analogia entre o processo da leitura e uma reação química. Na leitura, como na química, para termos uma reação é necessário levar em conta não só os elementos envolvidos, mas também as condições necessárias para que a reação ocorra. O simples confronto do leitor com o texto não garante a eclosão de todos os acontecimentos que caracterizam o ato da leitura. A produção de uma nova substância - no caso a compreensão - só ocorre se houver afinidade entre os elementos leitor e texto e se determinadas condições estiverem presentes. (LEFFA, 14996, p. 14)
\end{abstract}

Para tanto, nesse processo de interação texto-leitor é preciso considerar o conhecimento adquirido ao longo da vida do leitor (conhecimento prévio), pois só assim poderá se construir afinidade com o texto a ponto de compreendê-lo.

Alyousef (2005) também entende leitura como um processo que requer interação entre quem lê e o que está escrito, o que requer mais do que uma simples decodificação das palavras. Neste tipo de interação leitor-texto-autor, procuramos compreender o que o autor daquele texto quis expressar e, para isso, precisamos lê-lo como um todo, considerando quem escreveu, para quem escreveu, e quando escreveu. Este tipo de interação requer uma leitura mais atenta e crítica, em que estamos constantemente dialogando com o autor no intuito de checar as nossas hipóteses com as informações contidas no texto lido.

\title{
ESTRATÉGIAS DA LEITURA
}

De acordo com os PCN-LE (1998), mesmo inserido neste contexto escolar que impede ou dificulta o ensino das quatro habilidades comunicativas (falar, ouvir, ler e escrever), o ensino de Língua Estrangeira (LE) deve possibilitar o engajamento discursivo dos alunos, ou seja, a capacidade de se comunicar com outras pessoas através da LE. No contexto escolar brasileiro, isso pode ser feito através da leitura de textos e, a partir desta habilidade, os alunos poderão ser capazes de construir significados. Na leitura de textos em 
língua estrangeira, portanto, os PCN-LE (1998) sugerem que trabalhemos com o ensino de estratégias de leitura para que os alunos-leitores possam não apenas entender o que eles leem, mas também construir outros significados, outros olhares com base em suas experiências de vida e de mundo.

$\mathrm{Na}$ teoria da Leitura (KLEIMAN, 2007), podemos identificar dois tipos de estratégias: estratégias cognitivas e estratégias metacognitivas. As estratégias cognitivas envolvem diferentes processos nos quais as pessoas usam, inconscientemente, as pistas linguísticas e extralinguísticas presentes nos textos a fim de entender melhor o que foi escrito.

Deste modo, podemos concluir que as estratégias cognitivas de leitura estão relacionadas basicamente aos processos automáticos que envolvem, desde a identificação das letras que levam à construção de palavras, até à organização sintática da frase, chegando ao reconhecimento do sentido que têm no texto. Por exemplo, ao nos depararmos com a seguinte frase: "Minha melhor amiga é muito legal, ela tem 18 anos", podemos entender a frase, primeiro por sua organização, coesão, conseguindo compreender que a pessoa que tem 18 anos (ela tem 18 anos) se refere à minha melhor amiga, uma correspondência que fazemos automaticamente, por estar relacionada aos aspectos linguísticos do texto e de meu conhecimento de mundo.

As estratégias metacognitivas, por outro lado, envolvem a habilidade de se estabelecer objetivos para a leitura, tendo como ponto de partida o conhecimento prévio do leitor. Através destas estratégias o leitor é levado a refletir sobre o texto antes mesmo de lê-lo, formulando hipóteses a partir de sua experiência de vida. A estratégia metacognitiva de leitura pode ser definida da seguinte forma: “(...) uma reflexão sobre o próprio conhecimento. [...] Esse conhecimento metacognitivo é desenvolvido ao longo dos anos de uma pessoa." (KLEIMAN, 2007, p. 34). Assim, o leitor avalia o texto antes de saber seu conteúdo, a partir de todo o conhecimento armazenado em sua memória. Por exemplo, ao olharmos a capa de uma revista com a imagem do atual presidente dos EUA, ativamos nosso conhecimento prévio sobre o assunto e levantamos hipóteses sobre a matéria de capa. Provavelmente, chegaríamos à conclusão de que a matéria falará sobre política e, a partir dessa hipótese que levantamos, decidiremos se o texto é ou não de nosso interesse.

Portanto, concordando com Kleiman (2007), entende-se por estratégia metacognitiva, um mecanismo de automonitoração da aprendizagem no processo de leitura. Isto é, uma vez que o leitor estabelece objetivos claros para as suas necessidades de leitor, tal leitor pode estabelecer que tipo de leitura fará. 
Com base nas definições sobre as estratégias de leitura, podemos visualizar nas aulas de leitura em LI, cuja ênfase está no desenvolvimento das estratégias de leitura dos alunos-leitores, três fases exploradas conhecidas como pré-leitura, leitura e pós-leitura. Segundo Dantas (2012) na fase de pré-leitura, o conhecimento de mundo do aluno é ativado, e através de informações separadas os alunos acabam por concluir de que trata o texto. Ao ler o título, uma imagem, o autor e a fonte de um texto, o aluno pode deduzir o assunto que será abordado nele. Uma das estratégias metacognitivas que podem ser utilizadas no momento da pré-leitura é o skimming.

Diversos autores (LINDSAY \& KNIGHT, 2006; KLEIMAN, 2007; DAVIES, 1995), discorrem sobre a estratégia skimming como uma forma de ler rapidamente para ter uma ideia geral do texto, sem se deter em detalhes. $\mathrm{O}$ foco está em ler tendo como base o conhecimento de mundo do aluno-leitor. Por exemplo, as atividades em sala de aula que estão geralmente associadas a este tipo de estratégia podem incluir leitura silenciosa para que a compreensão geral do texto seja possível, ou para que o tema do texto possa ser discutido em um debate com toda a turma.

$\mathrm{Na}$ fase da leitura, "o aluno projeta seus conhecimentos de forma a compreender o que o texto quer dizer, separando o que é importante e o que são detalhes" (DANTAS, 2012, p.141). Para este momento, recomenda-se a estratégia metacognitiva scanning. Por exemplo, a estratégia scanning é definida por Lindsay e Knight (2006) como um mecanismo de leitura em que alguém procura por informações específicas dentro de um texto. No caso, o aluno-leitor lê todas as informações presentes no texto e procura por informações específicas de acordo com perguntas de compreensão também específicas como: Onde é....? Quando foi...? Para quem é...?, etc. Um forma de utilizar esta estratégia é pedir que os alunos encontrem palavras que eles já conheçam ou palavras cognatas durante a leitura, ou, por exemplo, que procurem no texto respostas para perguntas como: De que trata o texto? Onde é encontrado? Quando foi produzido? Para quem é destinado? etc.

Já na fase de pós-leitura, “o aluno-leitor é levado a refletir sobre o texto, o que pode ser feito através de exercícios de interpretação textual. Esses exercícios fazem com que o aluno pense sobre o que leu e procure encontrar respostas a partir do que está escrito, ou em aspectos sociais que estejam relacionados ao texto de alguma forma" (DANTAS, 2012, p. 142). Para ilustrarmos a atividade, podemos voltar ao exemplo da matéria sobre o presidente Obama. Imaginem que os alunos tenham lido um texto sobre a política nos EUA, as eleições, o processo de votação, etc. Poderíamos pedir que os alunos 
comparassem as eleições e o sistema político dos EUA com as eleições e o sistema político do Brasil, apontando semelhanças e diferenças e também dando sua opinião sobre as características dos dois países. São estes fatores que caracterizam uma atividade de pósleitura, isto é, as atividades que procuram trazer à tona o que o texto aborda juntamente com o conhecimento de mundo do aluno-leitor; são tarefas que promovem reflexão e pensamento crítico. Os exercícios de escrita podem ser considerados bons exemplos de atividades de pós-leitura a serem explorados em salas de aula.

\section{MODELOS DE LEITURA}

Há também os modelos de leitura que incluem características das fases e estratégias de leitura (cognitivas e metacognitivas), e propõem diferentes formas de abordar os textos no ambiente de ensino e aprendizagem. Os modelos mais conhecidos e mais estudados são os modelos: 1) ascendente, 2) descendente e 3) interativo (GOUGH, 1972; GOODMAN, 1988; RUMELHART, 1977 apud DAVIES, 1995, p. 59 e 63).

O modelo ascendente está relacionado à leitura decodificada das letras. Quer dizer, o leitor lê letra por letra com o objetivo de reconhecer a palavra, chegando, assim, ao seu significado e ao significado texto. O leitor que utiliza este modelo de leitura normalmente considera o texto a única fonte de conhecimento, sendo os elementos linguísticos os únicos que formam e dão sentido ao texto. (GOUGH, 1972 apud DAVIES, 1995, p. 59).

$\mathrm{O}$ modelo descendente inclui o leitor no momento da leitura, e se associa às estratégias metacognitivas de leitura. Deste modo, só se chega ao significado do texto quando o leitor participa, adicionando suas hipóteses e seus conhecimentos prévios ao processo de compreensão. Tal modelo considera o conhecimento de mundo do leitor a principal fonte motivadora para a construção do significado no texto ( GOODMAN, 1988 apud DAVIES, 1995, p.59). Neste sentido, Kleiman afirma:

O processamento de um texto [...] se faz tanto a partir do conhecimento prévio e das expectativas e objetivos do leitor (chama-se esse processamento descendente ou decima-para-baixo) quanto a partir de elementos formais do texto à medida que o leitor os vai percebendo (chama-se esse processamento ascendente, ou de-baixo-para-cima). (KLEIMAN, 2007, p. 55)

Existe, também, o modelo interativo que é pautado na união dos dois modelos citados acima: o ascendente e o descendente. É dito que existe uma interação entre o autor e o leitor no momento da leitura, em que ambos têm a responsabilidade de construir o significado do texto (RUMELHART, 1977 apud DAVIES, 1995, p.63). Neste modelo, o 
autor escreve para tornar a leitura de seu texto compreensível, usando elementos linguísticos (também conhecido como pistas de contextualização) que guiem o leitor para identificar a intenção comunicativa do autor. Esse modelo, portanto, considera a união de todos os tipos de conhecimento, quando forem necessárias, de acordo com a necessidade de cada leitor. Isto é, caso o leitor tenha falhas quanto ao vocabulário do texto lido, este leitor poderá usar o modelo descendente para usar suas hipóteses como norteador de compreensão leitora. Quando, por sua vez, o leitor tem dificuldades em compreender a construção sintática dos textos, o modelo ascendente torna-se fundamental. Uma vez compreendendo melhor como as frases e as sentenças estão sendo construídas, melhor o leitor compreenderá a função das sentenças e dessas frases para atingir a compreensão geral do texto. Dependendo do objetivo do leitor, ora em decifrar o texto ora em captar a compreensão geral, os dois ou apenas um dos processos de leitura citados deverá ser utilizado. É o que chamamos de modelo interativo de leitura; quando fazemos uso dos dois ou de apenas um dos dois, para cumprir nossas metas de leitura.

\section{CRENÇAS DE APRENDIZES SOBRE LEITURA EM LÍNGUA INGLESA}

Ao estarmos inseridos em qualquer contexto social ou cultural, observamos e adquirimos crenças, ou seja, passamos a acreditar em alguns fenômenos tomando-os como verdade absoluta em nossas vidas. Estes fenômenos estão, muitas vezes, relacionados a ideias generalizadas, pertencentes ao senso comum.

$\mathrm{O}$ conceito de crença muda quando relacionado à Linguística Aplicada. Para Barcelos (1995) as crenças estão relacionadas à cultura de aprender, que pode ser definido da seguinte maneira:

\footnotetext{
Conhecimento intuitivo implícito (ou explícito) dos aprendizes constituído de crenças, mitos, pressupostos culturais e ideais sobre como aprender línguas. Esse conhecimento, compatível com sua idade e nível socioeconômico, é baseado na sua experiência educacional anterior, leituras prévias e contatos com pessoas influentes. (1995, p. 50)
}

No âmbito educacional, as crenças também estão relacionadas às experiências de vida do indivíduo, mas relaciona-se principalmente às experiências de aprendizagem. No nosso caso, estão relacionadas às experiências com a linguagem e com a forma de lidar com a leitura em LI. Para Barcelos (2004), a visão do aluno sobre a natureza da linguagem e a aprendizagem de uma língua estrangeira está relacionada à vivência dos alunos com a educação e com a forma de suas reações a essa experiência. 
Ou seja, professores, alunos e demais membros da comunidade escolar (diretores, coordenadores, orientadores pedagógicos), por exemplo, tendem a carregar diversas crenças sobre ensino-aprendizagem de língua inglesa de um modo geral. E quando nos referimos ao ensino de línguas estrangeiras no Brasil, não é difícil ouvir algumas pessoas dizerem: "Na escola só se aprende o verbo to be", ou "Só se aprende inglês de verdade em cursinho de línguas", ou ainda "É impossível aprender inglês na escola". Estas crenças são resultado das experiências vividas por estas pessoas no processo de ensino-aprendizagem, e "referem-se ao que o aprendiz acredita ser verdadeiro sobre esses [...] processos, dada uma certa concepção do que eles são" (BENSON \& LOR, 1999, p. 464).

Portanto, é possível inferir que alunos, por acreditarem que o ensino de língua inglesa nas escolas é de difícil acesso, não se esforçam para mudar esta realidade muitas vezes porque estão acomodados com a atual forma de aprender esta língua. Para os PCN LE, (1998), professores e alunos devem se esforçar para mudar o contexto de ensinoaprendizagem de LE e, "deve-se encontrar maneiras de garantir que essa aprendizagem deixe de ser uma experiência decepcionante, levando à atitude fatalista de que a língua estrangeira não pode ser aprendida na escola." (BRASIL, 1998, p.65). Ou seja, deve-se parar de pensar a situação de ensino-aprendizagem de língua inglesa como imutável, e tomar atitudes que transformem esta realidade.

Concordamos com Barcelos (2004) quando discorre sobre a importância de trabalhar com as necessidades e crenças dos alunos, pois acreditamos que o professor deve se preocupar com a opinião de seus alunos, buscando sempre uma forma inovadora e interessante de transmitir o conhecimento. Usando as palavras da autora:

Essa preocupação, [...] continua ainda hoje, em desvendar o mundo do aprendiz, isto é, seus anseios, preocupações, necessidades, expectativas, interesses, estilos de aprendizagem, estratégias e, obviamente, suas crenças ou seu conhecimento sobre o processo de aprender línguas. (BARCELOS, 2004, p.5)

O trabalho na sala de aula, pelo olhar das crenças dos alunos sobre o que é e para que serve a leitura em Língua Inglesa, possivelmente pode ser de grande valia para nós professores por trazer à tona questões subjetivas quanto ao ato de ler. Os tópicos a serem lidos, os estilos de leitura a serem seguidos e as estratégias que cada aluno-leitor possa utilizar poderá ser um dos mecanismos a ser trabalhado em sala de aula para, talvez, alcançarmos a tão sonhada aula de leitura fluida, dinâmica e significativa para nós, professores e para os alunos. 


\section{METODOLOGIA}

Por se tratar de um grupo específico, a pesquisa é caracterizada como um estudo de caso. De acordo com Gonçalves (2003), o estudo de caso é o tipo de pesquisa que privilegia um caso particular, suficiente para análise de um fenômeno, sugerindo possibilidades para a modificação de uma determinada realidade.

Este trabalho também é caracterizado como uma pesquisa qualitativa. Para Oliveira (2003), esta modalidade de pesquisa não se baseia apenas na quantificação dos dados, mas é fundamentada na descrição dos significados e características das informações, comumente obtidas através de entrevistas ou questionários.

A pesquisa foi desenvolvida em uma Escola Estadual de Ensino Fundamental e Médio, situada em um bairro de classe média, em Campina Grande-PB. A quantidade de alunos por turma varia de 35 a 50 estudantes. A turma escolhida é de segundo ano do ensino médio, em que estão matriculados 38 alunos, com a faixa etária entre 15 e 19 anos. De acordo com a direção da escola, a maioria deles pertence à classe média. A professora da turma me informou, numa conversa informal, que eles são tranquilos e não muito interessados em participar das aulas.

Os dados da pesquisa foram obtidos através de um questionário composto de 7 perguntas. A escolha da aplicação do questionário foi baseada nas vantagens oferecidas por esse instrumento de coleta de dados que, segundo Rampazzo (2002), proporciona economia de tempo para o pesquisador, anonimato para os participantes, e atinge um maior número de respondentes, obtendo respostas mais precisas. O objetivo do questionário (apêndice A) foi procurar verificar as crenças dos alunos em relação às aulas de leitura em língua inglesa e considerava as seguintes questões: 1) o grau de interesse dos alunos na leitura dos textos em Inglês; 2) o grau de dificuldade na leitura em língua inglesa; e 3) os seus motivos para ler em língua inglesa. Este questionário foi aplicado na turma citada, no primeiro bimestre do ano letivo de 2012, antes da aula de inglês, e os alunos levaram em média meia hora (30 minutos) para respondê-lo.

É importante pontuar que alguns alunos matriculados na turma não estavam presentes no dia da coleta de dados, outros não quiseram participar da pesquisa e, por estes motivos, apenas 30 alunos da turma responderam ao questionário. Nove dos questionários não foram analisados por conter respostas confusas ou não compatíveis com as perguntas; 
assim, os outros vinte um questionários constituíram o corpus desta pesquisa e podem ser consultados nos apêndices.

\section{DISCUSSÃO}

Nesta parte, mostraremos, à luz dos questionários aplicados aos alunos, quais são as crenças mais recorrentes relacionadas ao ensino-aprendizagem de leitura em LI. A seguir, pontuaremos os principais motivos que os levam a prosseguir (ou não) na leitura em LI no contexto escolar. Por último, enfatizaremos as dificuldades que esses alunos apresentam nas atividades de leitura em sala de aula. Nas considerações finais, apontaremos como esses aspectos servirão para discutirmos as implicações pedagógicas no ensino da leitura.

\section{Crenças dos alunos}

No que concerne às crenças dos alunos, as perguntas 6 (Como você acha que deveria ser uma aula de leitura em inglês?) e 7 (Você considera a leitura em inglês importante? Por quê?) nos nortearam para verificar as expectativas dos aprendizes nas aulas de leitura em LI. A opinião dos alunos varia em relação ao que acontece nas aulas de leitura em língua inglesa. A maioria dos alunos afirmou que as aulas deveriam ser mais dinâmicas, divertidas ou interativas, como podemos ver nos exemplos a seguir.

\section{Ex. 1: "interativa, animada, ter dinâmicas e brincadeiras com as palavras em inglês"}

Ex. 2: "deveria ser bem dinâmica e alegre, pois assim a gente aprende mais",

De acordo com as respostas destes alunos, podemos inferir que as aulas de leitura não são interativas, dinâmicas, nem divertidas. Eles anseiam por aulas que os motivem, que sejam diferentes de sua realidade escolar. As respostas obtidas nos levam a inferir que eles estão inseridos num contexto escolar desmotivador, cansativo e desinteressante, como mencionado pelos PCN-LE (2000) quando afirmam que as aulas acabaram por assumir uma feição monótona e de caráter desmotivador.

Por outro lado, alguns alunos afirmam que as aulas de leitura deveriam seguir o mesmo critério adotado pela atual professora, ou seja, ter o mesmo padrão de leitura e tradução de textos por parte do professor. Podemos observar estas crenças nas respostas a 
seguir, quando, ao responderem a mesma pergunta, dois alunos afirmam que a aula deveria ser:

Ex.1: "do jeito que a professora dá, lendo e traduzindo conosco”,

Ex.2: "acho que da maneira que aprendemos é legal. Leitura pausada, tendo interpretação ao término da leitura, ou seja, a tradução”.

Com base nestas respostas, podemos perceber que algumas crenças são diferentes; elas se contradizem. Enquanto alguns alunos desejam aulas diferentes e dinâmicas, outros se satisfazem com o modelo de leitura e tradução de textos que não permite interação do aluno com o que está escrito. Nestas aulas, o professor lê o texto em inglês, usa a tradução e o aluno recebe a informação sem ser questionado, sem fazer esforço algum, sem sequer tentar ler e compreender o texto sozinho. $\mathrm{O}$ aluno se acomoda a esta realidade, de estar dependendo do professor para ler, acreditando que ele está aprendendo quando, na maioria das vezes, não está, pois o texto é lido, traduzido e discutido em português pelo professor, deixando, muitas vezes, a LI de lado.

Embora a tradução possa ser vista como um instrumento de ajuda, quando os alunos-leitores apresentam dificuldades de vocabulário e o contexto do texto não os ajuda a esta compreensão, por exemplo, o uso excessivo desta ferramenta pode atrapalhar na compreensão leitora em LI. De acordo com as respostas destes alunos, podemos inferir que eles estão mais acostumados em lidar com a tradução como mecanismo de ajuda do professor para facilitar a compreensão leitora em LI e não para ajudá-los a compreender, sozinhos, a leitura em questão. Esta dependência que os alunos têm do professor para prosseguir às leituras em LI podem ser vistas, então, nas respostas dadas pelos alunos.

Podemos inferir, com base nestes dados, que os alunos gostam das aulas de leitura em seu contexto atual de ensino e tendem a acreditar que o trabalho de tradução é importante porque eles descobrem o significado das palavras. Podemos relacionar essa preocupação em traduzir textos ao fato de eles estarem se preparando para participar de vestibulares e concursos, já que estão no $2^{\circ}$ ano do ensino médio e a exigência para ler em LI é maior. Podemos também concordar com os PCN-LE (1998) quando apresentam a leitura como a principal habilidade a ser trabalhada nas escolas públicas regulares, por acreditar que ela atende às necessidades da educação formal, sendo a habilidade comunicativa que o aluno usa em seu contexto social imediato, isto é, provas de vestibulares, concursos, etc. 
Também questionamos a importância que a leitura em LI pode ter na vida destes alunos. A pergunta trouxe à tona a importância da LI na atualidade e veio confirmar a necessidade que muitos precisam deste idioma no meio profissional, ou para se comunicar com pessoas de outros países. Tal justificativa se deve, possivelmente, por termos uma crescente necessidade, por exemplo, em interagir em língua inglesa na internet nas mais diversas formas de comunicação digital (emails, Facebook, chats, blogs). Quanto à questão profissional, muitos jovens associam a necessidade de ler em LI para poder obter um bom emprego, para poder alcançar melhores condições de trabalho, conforme resposta abaixo explicita, ou para não ficar por fora do que acontece no mundo, pois grande parte das notícias do mundo é circulada na internet, através da língua inglesa. Podemos confirmar tais afirmações ao observar os trechos abaixo, conforme a questão 7 (Você considera a leitura em inglês importante? Por quê?)

\section{Ex.1: "sim, pois o inglês é uma língua utilizada mundialmente.".}

Ex.2: "Considero muito importante. Por que é uma língua que abre portas para o mercado de trabalho, e nos possibilita ter uma boa nota no ENEM/vestibular...".

Estas afirmações confirmam que os alunos tendem a considerar a importância da língua inglesa no mundo atual, uma vez que a língua é usada em diversos contextos internacionais. De acordo com Gadriot-Renard (2005), a LI se impõe a cada dia como língua franca por ser o idioma de mais fácil acesso e comunicação entre países. As respostas dos alunos também explicitam suas preocupações em relação ao mundo do trabalho e à possibilidade de ingressar em uma universidade que exige um teste formal escrito em que a leitura e compreensão de textos são necessárias para avaliação dos candidatos.

\section{Fatores que (des) motivam os alunos na leitura em LI}

Muitas vezes, os professores de língua inglesa se deparam com realidades nada acolhedoras em suas salas. Os alunos tendem a demonstrar resistência em aprender a língua, não participando das aulas, alegando não entenderem nada. Ao estarmos inseridas no contexto escolar através da disciplina de estágio supervisionado, pudemos perceber várias crenças dos alunos acerca disso. Por exemplo, é comum ouvir afirmações do tipo "sei disso não professora, não tô entendendo nada", ou ao serem questionados sobre algo durante a aula repetem: "sei falar inglês não, professora". 
Ao questionarmos estes alunos perguntando "Você gosta de ler textos em inglês?" (questão 1), obtivemos muitas respostas negativas. A maioria dos alunos afirmou não gostar da leitura em LI porque não entendem nada nas aulas. Outra parte dos alunos alegou não gostar por não saberem inglês, ou por não conseguirem traduzir o texto, por achar cansativo ou confuso, como podemos perceber nas respostas abaixo. Possivelmente, estas respostas se devem ao fato das aulas serem baseadas em leitura em voz alta e na tradução, logo em seguida, método de ensino muito comum nas aulas centradas no professor e característico no método de Gramática e Tradução (BARCELOS, 1995; LEFFA, 1996).

\section{Ex.1: "Não. porque não entendo nada"}

\section{Ex.2: "Acho interessante, mas acho inglês muito complicado".}

As respostas obtidas só confirmaram as constatações feitas anteriormente, que os alunos têm a crença de não saber inglês e internalizam esta afirmação, desistindo de aprender a língua "porque é difícil, porque é complicado, é confuso".

Estas afirmações nos remetem ao que os PCN-LE chamam de "atitude fatalista" (1998, p.65), que está relacionada às declarações dos alunos quando dizem que não entendem nada, e que a LI é complicada e confusa. Também concordamos com os PCNLE quando afirmam que deve-se parar de pensar a situação de ensino-aprendizagem de língua inglesa como imutável, e tomar atitudes que transformem esta realidade. Neste caso, os alunos deveriam tentar enxergar a aprendizagem de língua inglesa de uma forma diferente, se esforçando para aprender mais, e não só afirmando que é difícil e confuso. Acredita-se que, se os alunos participassem de forma ativa no processo de ensinoaprendizagem, e se comunicassem com o professor, expondo suas necessidades de aprendizagem, seria possível modificar as práticas de ensino já estabelecidas anteriormente, modificando a realidade das aulas de LI.

Por este motivo, consideramos relevante perguntar, também, quais os fatores que motivam estes alunos a ler em inglês, pois, se eles se sentem desmotivados a aprender a ler inglês na escola, existem motivos fora da escola que os motivam (ou não), a ler e compreender a língua inglesa. Eles foram questionados e nos forneceram respostas bem diferentes, como podemos verificar a seguir na Questão 4: "Existem motivos pelos quais você lê ou gostaria de ler em inglês? Quais?”

\section{Ex.1: "Sim, seria melhor para mim, posso precisar do inglês no futuro..."}


Ex.2: "Sim, existem uma variedade de jogos eletrônicos dos Estados Unidos que a maioria são inglês, ou seja, o idioma é inglês, e eu não entendo absolutamente nada, e por isso acho importante aprender inglês".

A partir dos dados obtidos, podemos perceber que a maioria dos alunos se sente motivada a ler porque a LI é importante nas suas vidas acadêmicas e profissionais. Outros se sentem motivados por gostarem da língua inglesa, e terem vontade de aprender uma nova cultura, com o objetivo de viajar para o exterior. Outros acreditam que aprendendo a ler inglês conseguirão se comunicar com outras nações e, por isso, se sentem motivados. Aproximadamente dois alunos querem aprender (a ler) inglês porque é a linguagem dos jogos eletrônicos, filmes e seriados, e outros afirmaram que gostariam de ler em inglês por acharem a língua bonita, ou porque é necessário para a escola.

Ao ler as respostas dos alunos percebemos que grande parte dos fatores que os motivam a ler em inglês não estão relacionados ao contexto escolar, não estão ligados à escola, à disciplina ou ao professor. São fatores relacionados a situações cotidianas, como assistir filmes, ou jogar vídeo game, ou ainda a situações importantes, relacionadas ao futuro acadêmico e profissional deles.

A partir da análise destes dados, podemos inferir que a maioria dos alunos enxerga a leitura em LI importante em suas vidas por ser uma língua franca, utilizada mundialmente como dito por Gadriot-Renard (2005). E podemos chegar à conclusão que eles consideram a leitura importante para suas vidas acadêmicas e profissionais, o que nos remete novamente aos PCN- LE (1998), que defendem o ensino de leitura nas escolas, por ser a habilidade que os alunos podem usar em seu contexto social, isto é, fazem uso dela ao participarem de seleções e concursos vestibulares.

\section{Dificuldades encontradas no processo de leitura}

Os alunos também foram questionados quanto ao modo de ler em inglês, pois consideramos importante saber quais são os caminhos que norteiam a leitura deles. Com base nas questões 2 "Como você lê textos em inglês? Tem alguma técnica ou estratégia que facilita a sua leitura?" e 3 (Você acha difícil ler textos em inglês? Quais são suas maiores dificuldades?), a maioria das respostas está relacionada à tradução do texto. Ou seja, muitos alunos ainda têm a crença de que só entenderão um texto em inglês se traduzirem palavra por palavra. Porém, alguns alunos pensam de modo diferente, e buscam outras maneiras de ler textos em LI. Podemos afirmar isso com base nas seguintes 
afirmações da Questão 2 (Como você lê textos em inglês? Tem alguma técnica ou estratégia que facilita a sua leitura?)

Ex.1: "Tento ler ele todo na primeira vez e na segunda vou traduzindo logo as palavras que conheço depois se não tiver mais palavras que eu saiba traduzir, uso o dicionário inglês".

Ex.2: "Se no texto houver alguma imagem, figura, fica muito fácil identificar o que o texto quer passar, e com isso o texto se torna mais legivel”.

Com isso, podemos perceber que, mesmo que a maioria acredite que a tradução do texto é o melhor caminho para a leitura e compreensão de textos em inglês, alguns deles têm o conhecimento, inconsciente ou não, de modelos e de estratégias de leitura. Com base nos exemplos 2 e 3, pode-se dizer que eles fazem uso dos dois modelos de leitura mais comuns, o modelo ascendente e o descendente. $\mathrm{O}$ modelo ascendente relaciona-se à leitura decodificada das letras. Quer dizer, o leitor lê letra por letra com o objetivo de reconhecer as palavras e os seus significados no texto (GOUGH, 1972 apud DAVIES, 1995, p. 59). Já o modelo descendente exige a participação do leitor no momento da leitura e só se chega ao significado do texto quando o leitor adiciona suas hipóteses e seus conhecimentos prévios ao processo de compreensão (GOODMAN, 1988 apud DAVIES, 1995, p. 59).

Podemos observar o uso do modelo ascendente no exemplo 3, quando o aluno diz buscar no texto palavras cognatas, as que são parecidas com o português, para facilitar a leitura. O modelo descendente, presente no exemplo 2, é o modelo que busca elementos extra textuais, relacionados a gráficos, imagens que ativam o conhecimento prévio do aluno, que faz inferências quanto ao assunto do texto, facilitando a leitura e a compreensão textual. Tal modelo pode ser observado quando o aluno afirma "Se no texto houver alguma imagem, figura, fica muito fácil identificar o que o texto quer passar...”.

Outro questionamento feito aos alunos foi sobre as dificuldades encontradas no momento da leitura em LI. Metade dos alunos afirmou que ler em inglês é difícil, e alegam não conseguir entender e/ou traduzir as palavras. Tal afirmação nos leva novamente à crença de que só se consegue ler/entender um texto em inglês se todas as palavras forem traduzidas. A outra parte dos alunos apontou dificuldades que, em sua maioria, não estão relacionadas ao momento de leitura, como não saber a pronúncia das palavras. Apenas dois alunos, exceto os 50\% citados anteriormente, apontaram dificuldades referentes à leitura, como podemos obervar abaixo nas respostas da Questão 3: Você acha difícil ler textos em inglês? Quais são suas maiores dificuldades? 
Ex.1: "Sim, por conta da ordem que as palavras, não é a mesma ordem que fica em português"

Ex.2: "Não, minha dificuldade é mais nas conjunções e com o tempo dos verbos".

Estas respostas nos fazem constatar que os alunos têm um vocabulário escasso da língua. Acreditamos que, por serem alunos do $2^{\circ}$ ano do ensino médio, deveriam conhecer mais palavras em inglês, não encontrando esta dificuldade tão grande no momento da leitura. Por outro lado, não sabemos como tem sido o processo de aprendizagem da língua inglesa até o momento de nossa pesquisa. Grande parte dos alunos afirma não conseguir ler em inglês por não saber pronunciar corretamente as palavras. Esta crença possivelmente está ligada à abordagem de ensinar dos professores, dando ênfase na leitura oral, na busca da compreensão do vocabulário antes da leitura, conforme discutimos anteriormente.

\section{CONSIDERAÇÕES FINAIS}

O presente trabalho foi escrito com o objetivo de pesquisar as crenças dos alunos, de uma turma de $2^{\circ}$ ano do Ensino Médio, a fim de verificar os fatores que os motivam na hora de ler em inglês, descrevendo também as principais dificuldades apresentadas por estes alunos nas aulas de LI. Com base nas respostas ao questionário aplicado, algumas implicações pedagógicas para o ensino-aprendizagem da prática de leitura em LI serão discutidas.

De acordo com Bezerra (2000), para que o ensino aprendizagem de LI ocorra de maneira satisfatória nas escolas regulares do Brasil, é preciso que haja mudanças metodológicas no trabalho com textos. Nas palavras de Bezerra,

Os professores (...) precisam pôr em prática, em sala de aula, o trabalho com textos, não para um estudo estéril de regras a serem memorizadas (e não seguidas), mas para que os alunos leiam/escrevam, procurando informar-se, formar-se e posicionar-se diante dos fatos. (BEZERRA, 2000, p. 76)

Deste modo, o professor precisa quebrar concepções, desfazendo o mito que pressupõe que o ensino de leitura em LE não funciona nas escolas regulares mostrando que o desenvolvimento da modalidade de leitura é uma tarefa possível. Isto é, devemos incluir em nossas aulas atividades de leitura que incentivem o aluno a refletir sobre sua realidade, 
e a realidade do texto, ativando o conhecimento prévio dele para que possa haver uma interação maior entre o aluno-leitor, o texto e autor.

Conforme os resultados sugerem neste artigo, podemos concluir que as aulas de leitura em LI são pautadas na tradução de textos por parte do professor, caracterizando uma aula cansativa que não chama a atenção dos alunos, nem para participar da leitura do texto. Acreditamos que as aulas de leitura deveriam seguir as três fases de exploração do texto - pré-leitura, leitura, e pós-leitura. O professor deveria centrar-se na fase da préleitura, buscando ativar, ou construir o conhecimento prévio necessário para o aluno compreender o texto a ser lido. O professor deveria também escolher textos que se aproximem da realidade social do aluno, para despertar neles o interesse pela leitura.

Com base no que apresentamos e discutimos neste trabalho, entendemos que, enquanto professores, devemos orientar e impulsionar o aprendizado de nossos alunos, mostrando a eles os caminhos, conscientizando-os de que eles são capazes de aprender inglês através da leitura. Acreditamos que, se este trabalho fosse feito em sala de aula, evitaríamos crenças como "não gosto porque não entendo nada" e poderíamos modificar o contexto atual de ensino, priorizando as qualidades de nossos alunos, não enaltecendo suas dificuldades.

Em suma, enquanto professores de línguas, devemos direcionar nosso olhar para os nossos alunos e tentar descobrir quais são suas crenças em relação ao processo de ensinoaprendizagem de inglês. Se estivermos conscientes das crenças de nossos alunos em relação ao que eles vivenciam na escola, estaremos aptos a enxergá-los de forma completa; em suas dimensões comportamentais, cognitivas, afetivas, sociais, culturais e políticas (LARSEN-FREEMAN, 1998).

\section{REFERÊNCIAS}

Alyousef, H.S. (2005) Teaching reading comprehension to ESL/EFL learners. In: The Reading Matrix. p.143-152.

Barcelos, A. M. F. (1995). A cultura de aprender língua es-trangeira (inglês) de alunos de Letras. Dissertação de Mestrado, UNICAMP.

(2004) Crenças sobre aprendizagem de línguas, Lingüística Aplicada e ensino de línguas. Linguagem \& Ensino. p. 123-156. 
Benson, P. \& Lor, W. (1999) Conceptions of language and language learning. System, 459472.

Bezerra, M. A. (2000). Leitura e Escrita: ainda desafios para o próximo milênio. João Pessoa: Graphos. 76.

BRASIL. (2010). LDB: Lei de Diretrizes e Bases da Educação Nacional: lei $\mathrm{n}^{\circ}$ 9.394, de 20 de dezembro de 1996. 5. ed. Brasília: Câmara dos Deputados. Edições Câmara

BRASIL. MEC. (1998). Parâmetros Curriculares nacionais: língua estrangeira / ensino fundamental. Brasília: MEC/SEF.

BRASIL. MEC. (2000). Parâmetros Curriculares nacionais: língua estrangeira / ensino médio. Brasília: MEC/SEF.

Dantas, D. (2012). Leitura e produção textual nas aulas de língua inglesa: um olhar sobre textos (auto) biográficos. In: DIAS, S. Formação de Professores de Língua Inglesa e Estágios Supervisionados: da reflexão à ação. Campina Grande: Realize Editora. p. 132149

Davies, F. (1995). Introducing Reading. London: Penguin English.

Gadriot-Renard, H. (2005). O Inglês: língua franca das instituições internacionais. In: - A geopolítica do inglês. São Paulo: Parábola Editorial.

Gonsalves, E. P. (2003). Escolhendo o percurso metodológico. In: Conversas sobre iniciação à pesquisa científica. Campinas: Editora Alínea. 67.

Kleiman, A. (2007). Texto e leitor: aspectos cognitivos da leitura. Campinas: Pontes.

Larsen-Freeman, D. (1998). Expanding the roles of learners and teachers in learnercentered instruction. In W. A. Re-nandya \& G. M. Jacobs (orgs.). Learners and language learning. Singapore: Seameo Regional Language Centre, 207-226.

Leffa, V. J. (1996). Aspectos da leitura. Porto Alegre: Sagra DC Luzzatto.

Lindsay, C \& Knight, P. (2006). Learning and Teaching English: a course for teachers. Oxford University Press. 89-64.

Oliveira, M. M. (2003). Redação de monografias, dissertações e teses. In: Como fazer projetos, relatórios, monografias, dissertações e teses. Recife: Edições Bagaço.

Paiva, V.L.M.O. (2003). A LDB e a legislação vigente sobre o ensino e a formação de professor de língua inglesa. In: Stevens, C.M.T e Cunha, M.J.Caminhos e Colheitas: ensino e pesquisa na área de inglês no Brasil. Brasília: UnB. 53- 84.

Rampazzo, L. (2002). Coleta, análise e interpretação dos dados na pesquisa descritiva. In: Metodologia Científica - para alunos dos cursos de graduação e pós graduação. São Paulo: Edições Loyola. 110-114. 


\section{AS AUTORAS}

Daniela Gomes de Araújo Nóbrega é licenciada em Letras - Português e Inglês (1997) pela Universidade Federal da Paraíba, possui Mestrado em Língua Inglesa e sua Literatura correspondente pela Universidade Federal de Santa Catarina (2002) e Doutorado em Letras e Linguística pela Universidade Federal de Alagoas (2011). É professora Doutora A da Universidade Estadual da Paraíba onde leciona no Curso de Letras- Inglês atuando, sobretudo, nas áreas de Leitura, Ensino-Aprendizagem em Língua Inglesa e Interação em sala de aula. É líder do Grupo de Pesquisa "Formação Docente em LE" onde se inserem trabalhos no campo da Linguística Aplicada em Língua Estrangeira (Inglês e Espanhol).

E mail: danielanobrega5@ gmail.com

Dione Barbosa Dantas é licenciada em Letras - Inglês pela Universidade Estadual da Paraiba (2012). Atuou como professora do Programa de Extensão em Línguas Estrangeiras oferecido pela UEPB no semestre 2011.1. Atualmente, é aluna especial do programa de pós-graduação em Linguagem e Ensino (Mestrado) da Universidade Federal de Campina Grande. Seus interesses de pesquisa estão voltados para a área de leitura e escrita em língua inglesa, ensino-aprendizagem em línguas estrangeiras e fonética em língua inglesa.

E-mail: dionedantas91@gmail.com

\section{APÊNDICES}

\section{QUESTIONÁRIO}

Universidade Estadual da Paraíba - UEPB

Centro de Educação - CEDUC II

Departamento de Letras e Artes - DLA

Curso de Letras - Habilitação em Língua Inglesa

Questionário Base para Trabalho de Conclusão de Curso - TCC

\section{Nome da Pesquisa: A percepção dos alunos em relação à leitura em Língua Inglesa}

Orientadora: Prof. Dra. Daniela Gomes de Araújo Nóbrega

Orientanda: Dione Barbosa Dantas

Esta pesquisa tem o objetivo de investigar a percepção que um grupo de alunos do $2^{\circ}$ ano do Ensino Médio tem em relação à leitura em Língua Inglesa. Desta forma buscamos respostas que nos possibilitem a identificação da sua concepção de leitura, a verificação das suas motivações para desenvolver esta habilidade na disciplina, e também a descrição das principais dificuldades que você encontra na prática de leitura em Língua Inglesa. Respondendo a este questionário você estará colaborando para o meu trabalho de conclusão de curso. Ao respondê-lo não é necessário por seu nome, todas as informações serão anônimas, e ninguém verá o que você escreveu. Sua opinião é muito importante! 
Obrigado pela sua ajuda!

\section{ORIENTAÇÕES}

1. Leia atentamente as questões e não deixe nenhuma em branco.

2. Responda francamente, sendo sincero ao dizer o que pensa.

3. Evite respostas evasivas, vagas e pouco claras como: Não / sim / um pouco / porque sim, etc. Tente responder claramente, explicando e/ou detalhando o motivo de suas respostas.

\section{QUESTÕES}

Questão 1 - Você gosta de ler textos em Inglês? Por quê?

Questão 2 - Como você lê textos em Inglês? Tem alguma técnica ou estratégia que facilita a sua leitura? Qual?

Questão 3 - Você acha difícil ler textos em Inglês? Quais são as suas maiores dificuldades?

Questão 4 - Existem motivos pelos quais você lê ou gostaria de ler em Inglês? Quais?

Questão 5 - Como o professor(a) ensina a leitura em Inglês? Você gosta? Por quê?

Questão 6 - Como você acha que deveria ser uma aula de leitura em Inglês?

Questão 7 - Você considera a leitura em Inglês importante? Por quê? 
Universidade Estadual da Paraíba - UEPB

Centro de Educação - CEDUC II

Departamento de Letras e Artes - DLA

Curso de Letras - Habilitação em Língua Inglesa

Questionário Base para Trabalho de Conclusão de Curso - TCC

\section{Nome da Pesquisa: A percepção dos alunos em relação à leitura em Língua Inglesa}

Orientadora: Prof. Dra. Daniela Gomes de Araújo Nóbrega

Orientanda: Dione Barbosa Dantas

Esta pesquisa tem o objetivo de investigar a percepção que um grupo de alunos do $2^{\circ}$ ano do Ensino Médio tem em relação à leitura em Língua Inglesa. Desta forma buscamos respostas que nos possibilitem a identificação da sua concepção de leitura, a verificação das suas motivações para desenvolver esta habilidade na disciplina, e também a descrição das principais dificuldades que você encontra na prática de leitura em Língua Inglesa. Respondendo a este questionário você estará colaborando para o meu trabalho de conclusão de curso. Ao respondê-lo não é necessário por seu nome, todas as informações serão anônimas, e ninguém verá o que você escreveu. Sua opinião é muito importante!

Obrigado pela sua ajuda!

\section{ORIENTAÇÕES}

1. Leia atentamente as questões e não deixe nenhuma em branco.

2. Responda francamente, sendo sincero ao dizer o que pensa.

3. Evite respostas evasivas, vagas e pouco claras como: Não / $\operatorname{sim} /$ um pouco / porque sim, etc. Tente responder claramente, explicando e/ou detalhando o motivo de suas respostas.

\section{QUESTÕES}

Questão 1 - Você gosta de ler textos em Inglês? Por quê?

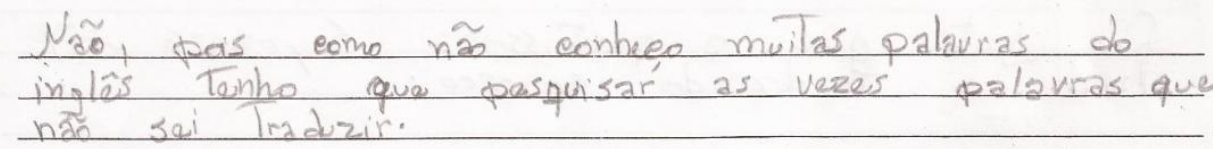

Questão 2 - Como você lê textos em Inglês? Tem alguma técnica ou estratégia que facilita a sua leitura? Qual?

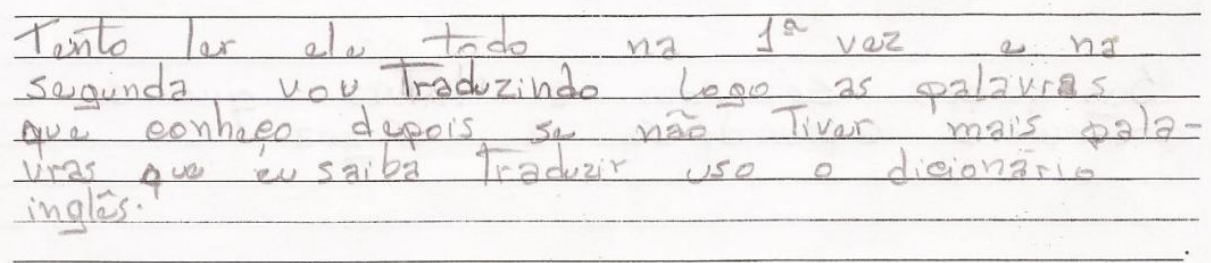


Questão 3 - Você acha difícil ler textos em Inglês? Quais são as suas maiores dificuldades?

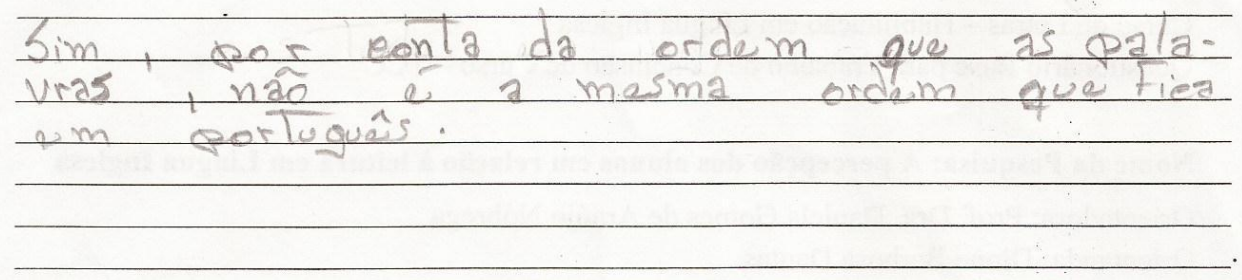

Questão 4 - Existem motivos pelos quais você lê ou gostaria de ler em Inglês? Quais?

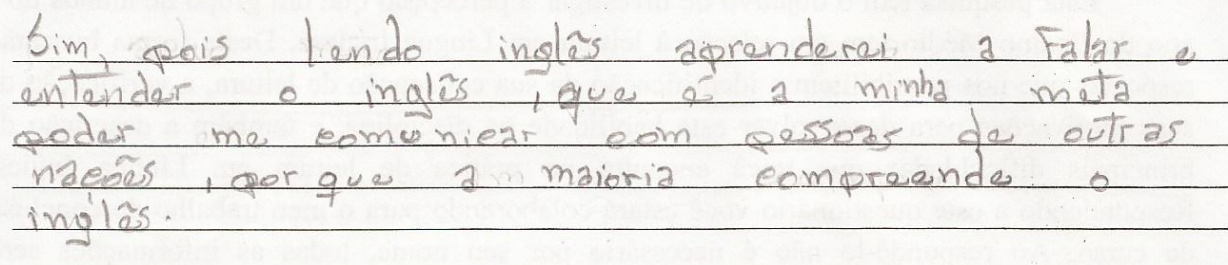

Questão 5 - Como o professor(a) ensina a leitura em Inglês? Você gosta? Por quê?

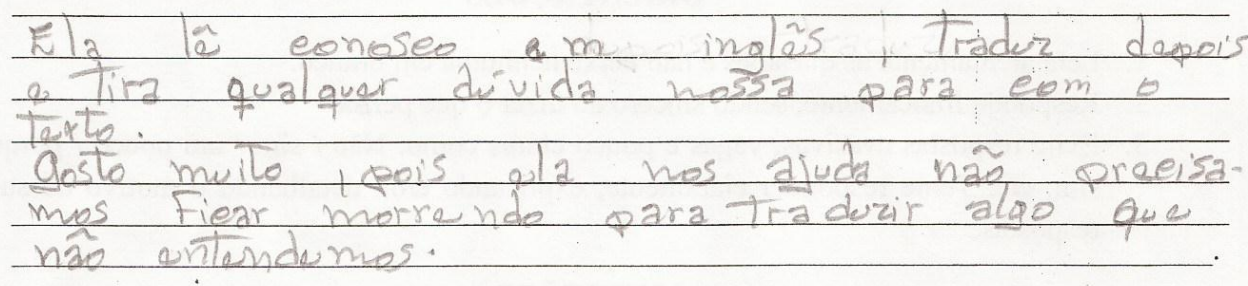

Questão 6-Como você acha que deveria ser uma aula de leitura em Inglês?

Do joito oue a profersora Sayonara daj

Questão 7 - Você considera a leitura em Inglês importante? Por quê?

Sim, pois só eam a laitura que se
pratiea a aprende-se a linoua.

